\title{
Herniated lumbar disc surgery in triathlon athletes with intraoperative neurophysiologic monitoring
}

\author{
Cirurgia de hérnia de disco lombar em atleta de triathlon \\ com monitoração neurofisiológica intraoperatória \\ Luciano Miller Reis Rodrigues $^{1}$, Fernando William Figueiredo da Rosa ${ }^{1}$, \\ Ricardo Jose Rodriguez Ferreira ${ }^{1}$, Fabrício Ueno ${ }^{1}$, Carlo Milani ${ }^{1}$
}

\begin{abstract}
Intraoperative neurophysiologic monitoring was performed in a patient by somatosensory evoked potential, motor evoked potential and free-running electromyography with intraoperative stimulation. It was verified that after decompression, there was an increase in the amplitude of motor evoked potential responses, showing an immediate improvement of the treated levels. Intraoperative neurophysiologic monitoring for surgical lumbar disc herniation in an athlete allowed a dynamic neurophysiological diagnosis, differentiation of the involvement of compression at the central or foraminal levels, and clinical awareness of the iatrogenic damage, thereby increasing safety.
\end{abstract}

Keywords: Intervertebral disk displacement/surgery; Athletes; Monitoring, intraoperative; Decompression, surgical; Case reports

\section{RESUMO}

Foi realizada em um paciente a monitorização intraoperatória neurofisológica com potencial somatossensitivo, motor e eletroneuromiografia contínua com estimulação intraoperatória. Depois da descompressão, ocorreu aumento da amplitude de resposta do potencial evocado motor, mostrando imediata melhora dos níveis tratados. A monitorização neurofisiológica intraoperatória para hérnia de disco lombar em um atleta permitiu um diagnóstico neurofisiológico dinâmico, diferenciação da compressão central ou foraminal e diagnosticar qualquer alteração iatrogênica aumentando a segurança.

Descritores: Deslocamento do disco intervertebral/cirurgia; Atletas; Monitorização intra-operatória; Descompressão cirúrgica; Relatos de casos

\section{INTRODUCTION}

The incidence of spinal injury during sports practice is estimated to affect between 10 to $15 \%$ of athletes, with approximately 0.6 to $1 \%$ of patients showing some associated degree of neurological deficit ${ }^{(1)}$. The injury mechanisms include flexion, extension, shearing, twisting and repetitive microtrauma caused by strength $^{(1,2)}$. There may be also soft tissue, intervertebral disc and bone injuries. The intervertebral disc injuries can reflect a form of early discopathy or traumatic disc herniation $^{(1,3)}$.

Intraoperative neurophysiologic monitoring (IONM) during lumbar surgery provides essential information to the surgeon regarding neural function, thereby avoiding potentially harmful surgical maneuvers and sequelae. IONM has become a useful tool in spine surgeries, indicated for degenerative, tumoral, trauma and deformity pathologies ${ }^{(4-15)}$.

The goal of IONM is to provide immediate feedback to the surgeon, thus avoiding permanent deleterious manipulation of neural tissues ${ }^{(1,14,15)}$. Several IONM methods are available, including the following: freerunning electromyography (EMG-FR) and stimulated electromyography (EMG-E); motor evoked potential (MEP) and somatosensory evoked potential (SSEP). Each modality monitors a specific nervous system function, and conceptually, multimodal monitoring becomes particularly important to identify spinal cord injuries during surgery ${ }^{(4-8)}$.

IONM is more frequently used in scoliosis surgery. The presence of neurological deficit with unchanged INMO is around $0.063 \%$. Prior to the use of IONM the rate of injury was about $1 \%$ in this type of surgery ${ }^{(5,6)}$.

In this case report the authors describe the use of IONM in lumbar spine surgery of bulky herniated discs in an athlete, in order to provide preoperatively 
a more precise diagnosis of the degree of nerve root involvement; to identify neural structures by stimulation; to provide early detection of nerve root insults by the responses obtained from the IONM preventing lesions; and to show IONM response improvement after surgical decompression.

\section{CASE REPORT}

The patient was a 22-years-old male triathlete, who usually trained 6 days per week, and who started to have lumbar pain over a period of 6 months without having stoped training. Two months later, after a competition, he presented severe pain that irradiated to the lower limb, so that he had to stop training.

During the physical examination, the patient referred pain at lumbar flexion, Lasègue's sign, decrease in dorsoflexion strength, grade IV in V of the right foot, and hypoesthesia in L5 and S1.

In the magnetic resonance imaging (MRI) exam of the lumbar spine, a degenerative discopathy was evident at three levels. The bulging of a herniated disc was observed in the L5-S1 right mid-lateral space (Figure 1).

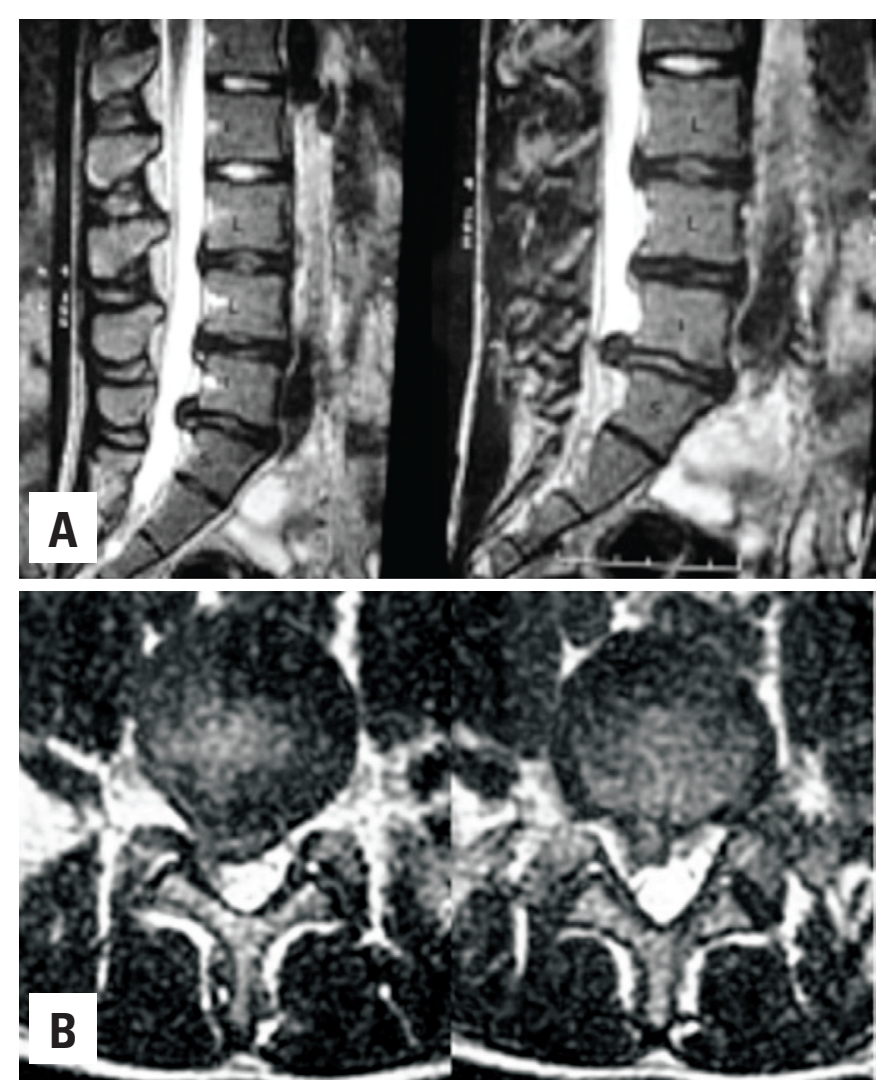

Figure 1. T2-weighted MRI showing lumbar disc herniation at the L5-S1 level. (A) Sagittal slice showing discopathy in three herniation levels at L5-S1. (B) Axial slice with bulging fragment on the right side
Early surgery was indicated because the athlete needed fast recovery to return to training routine and competitions.

The technique used was a mini decompression through a posterior midline incision, with the patient in prone position under general anesthesia. After dissection and removal of the paravertebral muscle of the affected side, laminectomy was performed at the level of the lumbar disc herniation. Then, the herniated fragment was removed.

During thesurgery intraoperative neurophysiologic monitoring was done using SSEP of the lower limbs (LL) with bilateral tibial nerve stimulation and $\mathrm{Cz}^{`}$ $\mathrm{Fz}^{\prime}$ cortical level capture (sist.10/20 EEG), MEP with electric transcranial stimulation of C3-C4 (sist.10/20 EEG), and also EMG-FR and EMG-E, with intraoperative stimulation through monopolar electrodes.

Myotome stimulation was completed for L3, L4, $\mathrm{L} 5, \mathrm{~S} 1$, and S2, as well as to the bilateral anal sphincter (S2, S3 and S4). Propofol and remifentanil were administrated intravenously without concomitant use of any type of inhaled medication or curative agents for anesthesia. The four-channel Keypoint (Dantec) was used. The electrodes used for muscle response capture of MEP, electromyography (EMG) and tibial nerve stimulation during SSEP of the LL were corkscrew and surface patches from SPES medica.

The surgery was monitored in preoperative, anesthetic postinduction SSEP and MEP measurements of the LL to trace the cortical response behavior patterns in the first and second myotomes and to define their degree of impairment.

During the exploration and decompression phases, EMG-FR and EMG-E were performed to better identify the neural structures, and to detect early any kind of injury. At the end of decompression, there was an increase in MEP response amplitudes, taken as an indication of immediate improvement of the treated levels.

During the surgery, monitoring showed a decrease in the compressed nerve root potential and an immediate improvement after resection of the herniated fragment (Figure 2). There was an improvement in the nerve root conduction after decompression upon electromyography (Figure 3).

\section{DISCUSSION}

The spinal cord and its muscles are biological structures with complex mechanics ${ }^{(1,14)}$. Bone resistance is higher during flexion and lower during tension, whereas ligaments are more resistant during tension. The viscoelasticity is an important characteristic of 

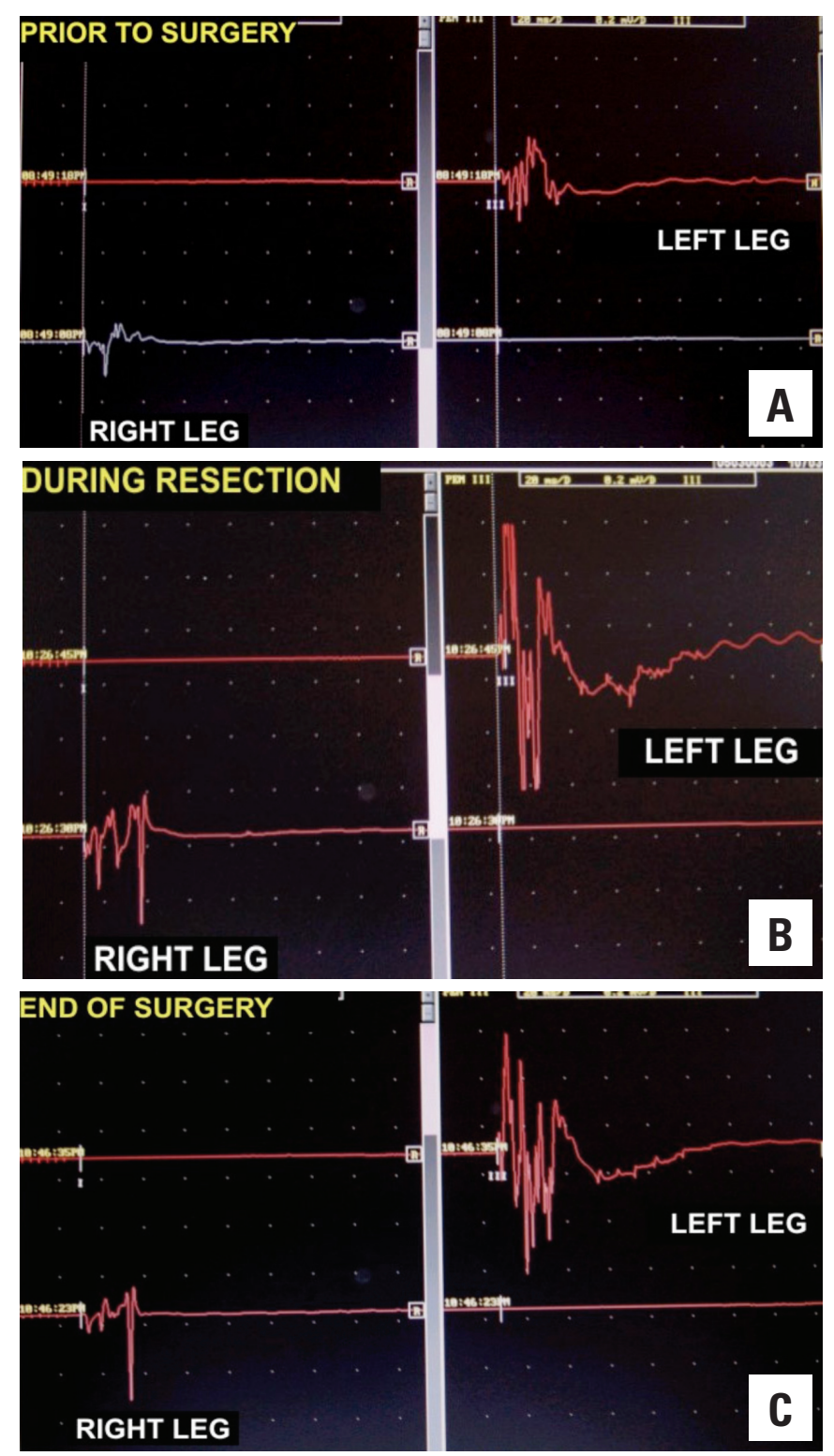

Figure 2. Motor evoked potential traced during lumbar discectomy surgery showing recovery of responses. (A) Prior to surgery. (B) During fragment resection. (C) End of surgery

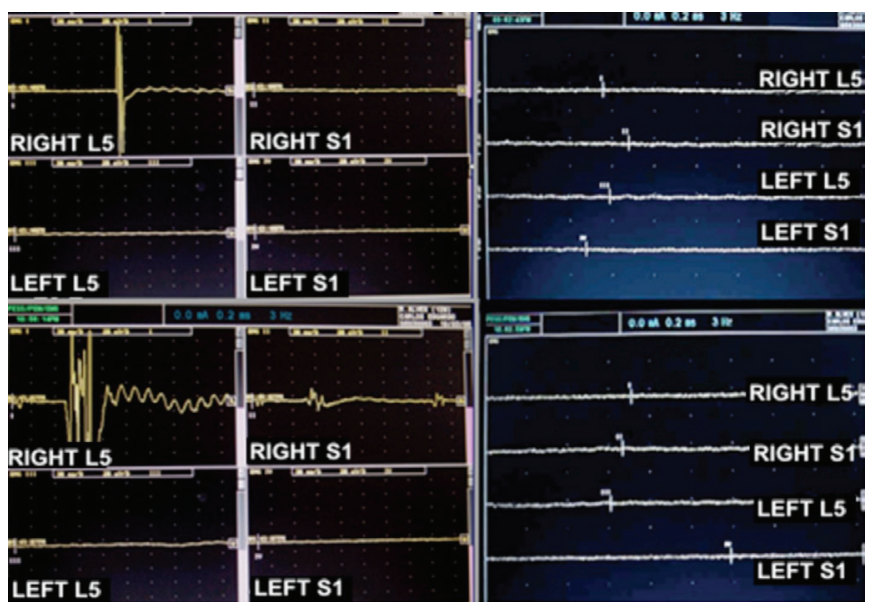

Figure 3. Electromyography: monitoring in which an improvement in myotome conduction was observed soft tissues, which gives hydraulic resistance to the compression. There is a continuous deformity depending on the length of time that the weight is applied as the system absorbs energy over a specific period, generally by hydraulic mechanism, which occurs in the disc when water is eliminated under pressure. Continuous or cyclical activities may affect this mechanism or even prevent it, causing early lumbar intervertebral disc degeneration $^{(1)}$.

The intervertebral disc is formed by an annulus with laminated structure composed of collagen fibers oriented $30^{\circ}$ from the horizontal axis. The internal fibers are connected to the cartilaginous endplate, whereas the external fibers are connected to vertebral body osseous structure and collagenous fibers, which function is basically to resist tension.

The nucleus pulposus is composed of a protein matrix, proteoglycans and water that acts as a gel, distributing tension in a regular pattern.

During compression, the nucleus and the internal fibers of the ring transmit forces from vertebra to vertebra, causing deflection of the adjacent vertebral plateaus, disc protrusion and development of annulus tension.

Excessive compression might cause endplate fracture mostly in activities that promote rapid charge or when there is weakness in the vertebral plateau due to age, causing a defect called Schmorl's nodule.

When the ring is submitted to excessive compression, it may result in dissection and dislocation of the nucleus pulposus and development of disc hernias ${ }^{(1-4,14)}$.

Every year, 20,000 discectomies are performed in Germany and around 200,000 in the United States. Patients that undergo this procedure usually are older than 40 years, although 1 to $3 \%$ of individuals submitted to this surgery are younger than 21 years old ${ }^{(2)}$.

There are two different ways to treat lumbar disc herniation. In the conservative treatment the patient undergoes rest, uses anti-inflammatory drugs, positional manipulations and several modalities of physiotherapy The second way is surgery followed by rehabilitation $^{(14,15)}$.

The surgery advantages are effective relief, reduced length of hospital stay (usually 1 day), and lower costs of the procedure. However, risks may happen during manipulation of the dural sac and nerve root. Paraesthesia may occur as well as damage to the dura mater. Infection and hematoma may also occur and in some cases requiring decompression to relieve pain and nerve root injury.

This patient was monitored with EMG, MEP and SSEP to protect and record the potential preoperative and postoperative responses. EMG during lumbar and thoracic surgery is a common procedure, which has 
a good correlation with intraoperatory handling of neural structures ${ }^{(7)}$.

EMG has high sensitivity, but presents low specificity to detect new postoperative neurological deficits or exacerbation of pre-existing deficits. Significant changes in the SSEP are not common and they have low sensitivity but high specificity ${ }^{(8)}$.

MEP shows high sensitivity and specificity when used in lumbar surgeries it shows significant alterations when the pre-, trans- and postoperative findings are compared. Therefore, the multimodal IONM with EMG, MEP and SSEP is useful to predict, and protect the integrity of the neural structures during surgical procedures.

An improvement of $30 \%$ in MEP responses after discectomy was observed, which showed an increase in performance of neural peripheral conduction. These findings suggest that the discectomy promotes an immediate improvement in root functioning and records the benefits of surgery in these athletes.

From a forensic standpoint, IONM presents a dynamic analysis of the injuries and evolution of the spinal cord and nerve roots in vertebral column surgeries, which is useful for the proper care of patients as a quantitative and qualitative tool. Furthermore, the use of IONM proved to be a valuable tool for evaluating acute improvements in this patient.

The use of IONM increased the safety of surgery, considering the patient was a professional athlete who do not only needed an efficient result, but a successful prognosis for the surgical decompression. These professionals need an aggressive rehabilitation program to promote a fast return to practice without affecting their performance. Return to sports at a competitive level was possible for this patient after a month of surgery, a goal was achieved after extensive hydrotherapy, core strengthening and maintenance of balance.

\section{CONCLUSION}

IONM has shown to be important in herniated lumbar disc surgery without instrumentation in a highperformance athlete because it allowed dynamic and complete diagnosis of the neural physiology showing the most damaged levels. It differentiated the severity of central and foraminal compression caused by disc herniation, and alerted the surgeon to the possible iatrogenic damage that may occur, thus increasing surgical safety.

\section{REFERENCES}

1. Basile Júnior R, Barros Filho TEP, Oliveira RP, Von Uhlendorff EF, Pedrosa FM, Nardelli J, et al. Lesões da coluna vertebral nos esportes. Rev Bras Ortop. 1999;34(2):90-6

2. Haher TR, O'Brien M, Kauffman C, Liao KC. Biomechanics of the spine in sports. Clin Sports Med. 1993;12(3):449-64

3. Hosea TM, Gatt CJ Jr. Back pain in golf. Clin Sports Med. 1996;15(1):37-53.

4. Lubitz SE, Keith RW, Crawford AH. Intraoperative experience with neuromotor evoked potentials. A review of 60 consecutive cases. Spine (Phila Pa 1976). 1999;24(19):2030-3.

5. Alemo S, Sayadipour A. Role of intraoperative neurophysiologic monitoring in lumbosacral spine fusion and instrumentation: a retrospective study. World Neurosurg. 2010;73(1):72-6.

6. Deletis V, Sala F. Intraoperative neurophysiological monitoring of the spinal cord during spinal cord and spine surgery: a review focus on the corticospinal tracts. Clin Neurophysiol. 2008;119(2):248-64.

7. Gunnarsson T, Krassioukov AV, Sarjeant R, Fehlings MG. Real-time continuous intraoperative electromyographic and somatosensory evoked potential recordings in spinal surgery: correlation of clinical and electrophysiologic findings in a prospective, consecutive series of 213 cases. Spine (Phila Pa 1976). 2004;29(6):677-84.

8. Sutter M, Eggspuehler A, Grob D, Jeszenszky D, Benini A, Porchet F, et al. The diagnostic value of multimodal intraoperative monitoring (MIOM) during spine surgery: a prospective study of 1,017 patients. Eur Spine J. 2007;16 Suppl 2:S162-70.

9. Shi YB, Binette M, Martin WH, Pearson JM, Hart RA. Electrical stimulation for intraoperative evaluation of thoracic pedicle screw placement. Spine (Phila Pa 1976). 2003;28(6):595-601.

10. Sala F, Palandri G, Basso E, Lanteri P, Deletis V, Faccioli F, et al. Motor evoked potential monitoring improves outcome after surgery for intramedullary spinal cord tumors: a historical control study. Neurosurgery. 2006;58(6):1129-43.

11. Skinner SA, Nagib M, Bergman TA, Maxwell RE, Msangi G. The initial use of free-running electromyography to detect early motor tract injury during resection of intramedullary spinal cord lesions. Neurosurgery. 2005;56/2 Suppl):299-314

12. Ulkatan S, Neuwirth M, Bitan F, Minardi C, Kokoszka A, Deletis V. Monitoring of scoliosis surgery with epidurally recorded motor evoked potentials (D wave) revealed false results. Clin Neurophysiol. 2006;117(9):2093-101.

13. Bose B, Wierzbowski LR, Sestokas AK. Neurophysiologic monitoring of spinal nerve root function during instrumented posterior lumbar spine surgery. Spine (Phila Pa 1976). 2002;27(13):1444-50.

14. Nair DR, Najm IM. Intraoperative neurophysiologic monitoring of the spine. In: Herkowitz HN, Rothman RH, Simeone FA, editors. The spine. Pennsylvania: Elsevier; 2006. p. 235-42.

15. Schwartz DM, Wierzbowski LR, Fan D, Sestokas AK. Surgical neurophysiologic monitoring. In: Vaccaro AR, Betz RR, Zeidman, SM, editors. Principles and practice of spine surgery. Phyladelphia: Mosby; 2003; p.115-26. 